\title{
A Simplified Approach to Fabricate a Custom-made Ocular Prosthesis
}

\author{
Nitai Debnath, Renu Gupta, A Meenakshi, K Ramkumar, Jiji John
}

\begin{abstract}
Loss of eye causes psychological trauma because of the facial disfigurement associated with the loss of facial structures. Rehabilitation with ocular prosthesis relieves this psychological trauma by restoring the lost facial structure and esthetics of the patient, thus aiding the individual in leading a normal, social and professional life.Though prefabricated ocular prostheses are available, due to better adaptation, comfort and esthetics custom-made ocular prosthesis is more preferable than prefabricated stock shells. This article aims at describing a simplified technique to fabricate a custom-made ocular prosthesis.
\end{abstract}

Keywords: Ocular prosthesis, Evisceration, Enucleation, Exenteration, Characterized prosthesis.

How to cite this article: Debnath N, Gupta R, Meenakshi A, Ramkumar K, John J. A Simplified Approach to Fabricate a Custom-made Ocular Prosthesis. Int J Prosthodont Restor Dent 2013;3(1):25-29.

\section{Source of support: Nil}

\section{Conflict of interest: None}

\section{INTRODUCTION}

The unfortunate loss of an eye has a psychological ill effect on the physical and social life of an individual..$^{1-3}$ Loss of an eye can occur due to trauma, congenital malformation and surgical removal of an uncontrolled growth of the ocular tissue or for the need of histological confirmation of a suspected diagnosis. ${ }^{4}$ Depending upon the severity surgical management may include: evisceration, enucleation or exenteration. Evisceration is a surgical procedure wherein the intraocular contents of the globe is partially removed, leaving the sclera, Tenon's capsule, conjunctiva, extraocular muscles and optic nerve intact. Enucleation is the surgical removal of the globe and a portion of the optic nerve from the orbit. Exenteration is the en bloc removal of the entire orbit, usually involving partial or total removal of the eyelids, and is performed primarily for eradication of malignant orbital tumors. ${ }^{5}$ Ocular prosthesis is advocated to rehabilitate the defects caused by evisceration or enucleation. Ocular prosthesis can be classified as stock shell and custom-made prosthesis. Custom-made ocular prosthesis shows intimate contact with the tissue bed, distributes the pressure more equally than stock prosthesis and decreases the incidence of conjunctival abrasion. ${ }^{2,6}$ This intimate tissue contact improves the tissue health by reducing fluid accumulation in tissue prosthesis interface. Fluid accumulation can cause tissue irritation and increased bacterial growth. ${ }^{6}$

This case report describes a simplified technique to fabricate an acrylic custom-made ocular prosthesis for an eviscerated ocular socket.

\section{CASE REPORT}

A 65-year-old male patient reported to the Department of Prosthodontics, with the chief complaint of facial disfigurement due to shrunken eyelids of the left eye (Figs $1 \mathrm{~A}$ and $\mathrm{B}$ ). History reveals a stab injury with a sickle of left eye due to an accidental fall from a tree before 2 years. The patient was diagnosed with a large hematoma and swelling of the left eye. Damaged ocular tissue and partial content of the left eye ball were surgically removed by the surgeons in order to relieve pain from hematoma. No ocular conformer or immediate ocular prosthesis was given during
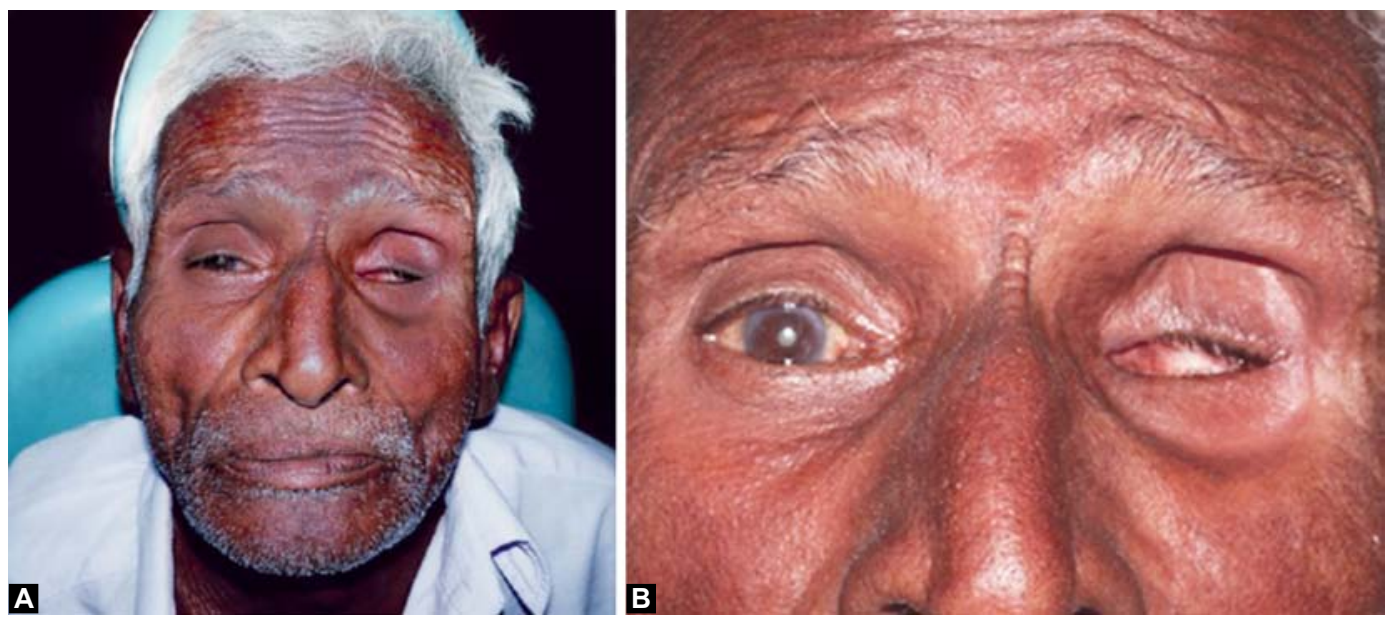

Figs $1 \mathrm{~A}$ and $\mathrm{B}$ : Preoperative photographs 
last 2 years. On examination, the patient had evisceration type of defect and the intraocular tissue bed was healthy with adequate depth beneath the upper and lower fornices for the retention of prosthesis.

A custom acrylic resin ocular prosthesis was planned for the patient. An informed consent was obtained from the patient prior to the procedure. A total of $2 \%$ lignocaine hydrochloride topical gel was applied on the ocular tissues of left eye to reduce the tissue irritability of mucosa while making impression. The socket was cleaned by irrigating with a cold saline solution and dried with cotton pellets. Eyebrows and eye lashes on the defect side were lubricated with petroleum jelly.

With the patient seated in a semireclined position, boxing of the facial outline was done with modeling wax (Modeling wax, DPI, India). The impression of face was registered with a slow setting alginate impression material (Algitex, DPI, India) with an overlying plaster support. The impression was poured in dental stone (Ultrastone, Kalabhai, India); thus, a facial model was obtained (Fig. 2A). A sheet of modeling wax was used as spacer and a custom ocular tray of left eye was made with clear acrylic resin on the facial model (Trevalon Clear, Dentsply, India) (Fig. 2C). A hollow plastic cap of a $2 \mathrm{ml}$ disposable syringe was attached on the center of the tray with autopolymerizing resin (RR cold cure, DPI, India) (Fig. 2B) and multiple holes were made on the tray. The tray extensions were adjusted in the ocular socket. Fast-setting vinyl polysiloxane impression material (Elite HD Light Body, Zhermack, Italy) was injected into the eye socket through the hollow plastic tube and impression was recorded under the functional movements of the ocular muscles (Fig. 2D).

The impression was poured with split-cast procedure (Figs 3A and B). Wax sclera blank was made in the split cast with ivory wax (Hi-tech wax, Pearson, USA). The wax sclera blank was tried in the ocular socket and fullness of the eyelid adjusted. An imaginary vertical line was drawn on the right side of the face which passes through the pupil of right eye. Similarly, a second vertical line was drawn on the left side of the face keeping the equal horizontal distance from the midline. Thereafter, the position of pupil and diameter of the iris was marked in the wax sclera blank. A stock eye shell was selected whose color and size of iris matches with the right natural eye of the patient (Fig. 3C). The selected iris
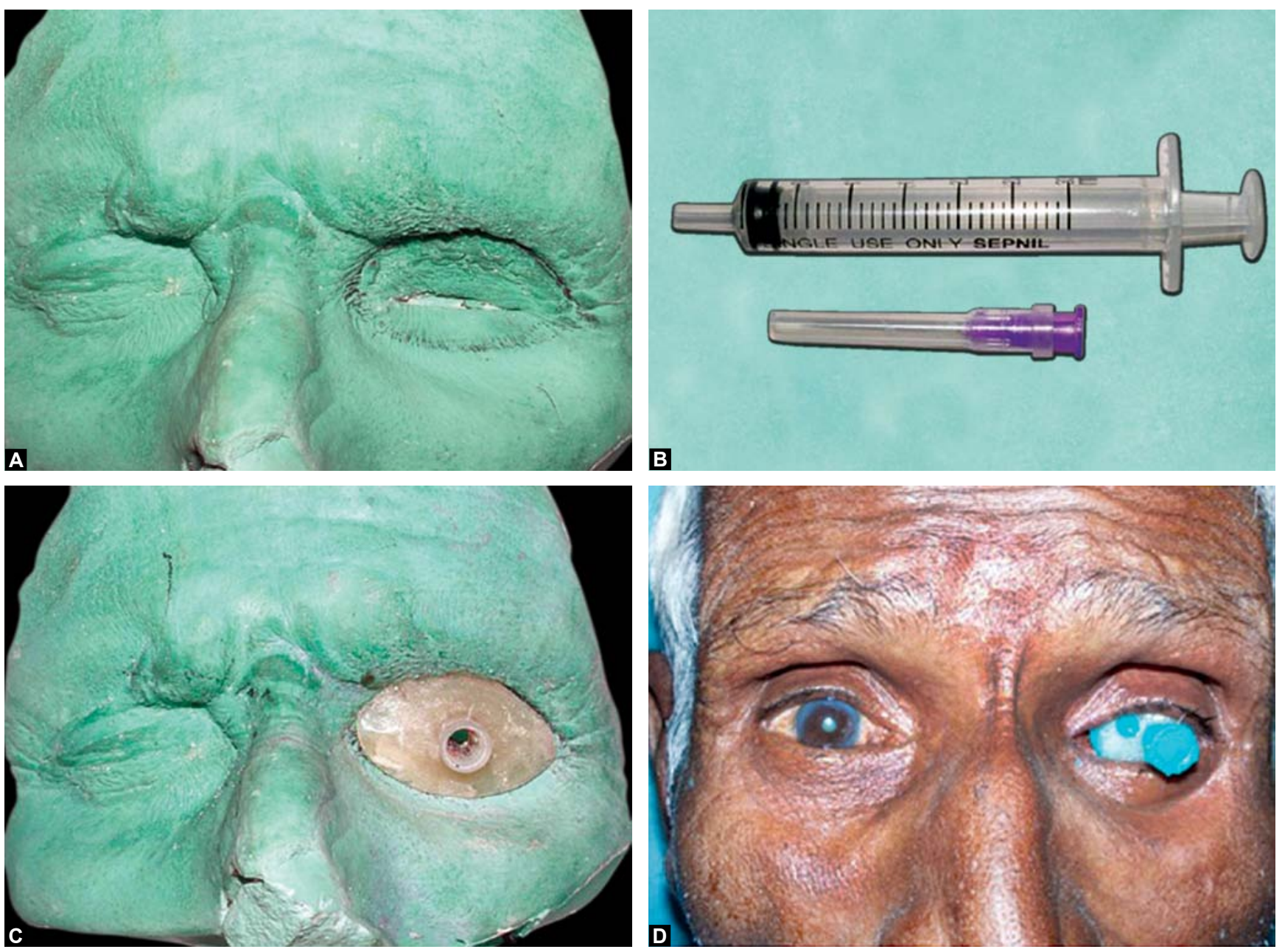

Figs 2A to D: Impression procedure of ocular defect: (A) facial model, (B) $2 \mathrm{ml}$ disposable syringe,

(C) custom ocular tray, (D) impression registration 

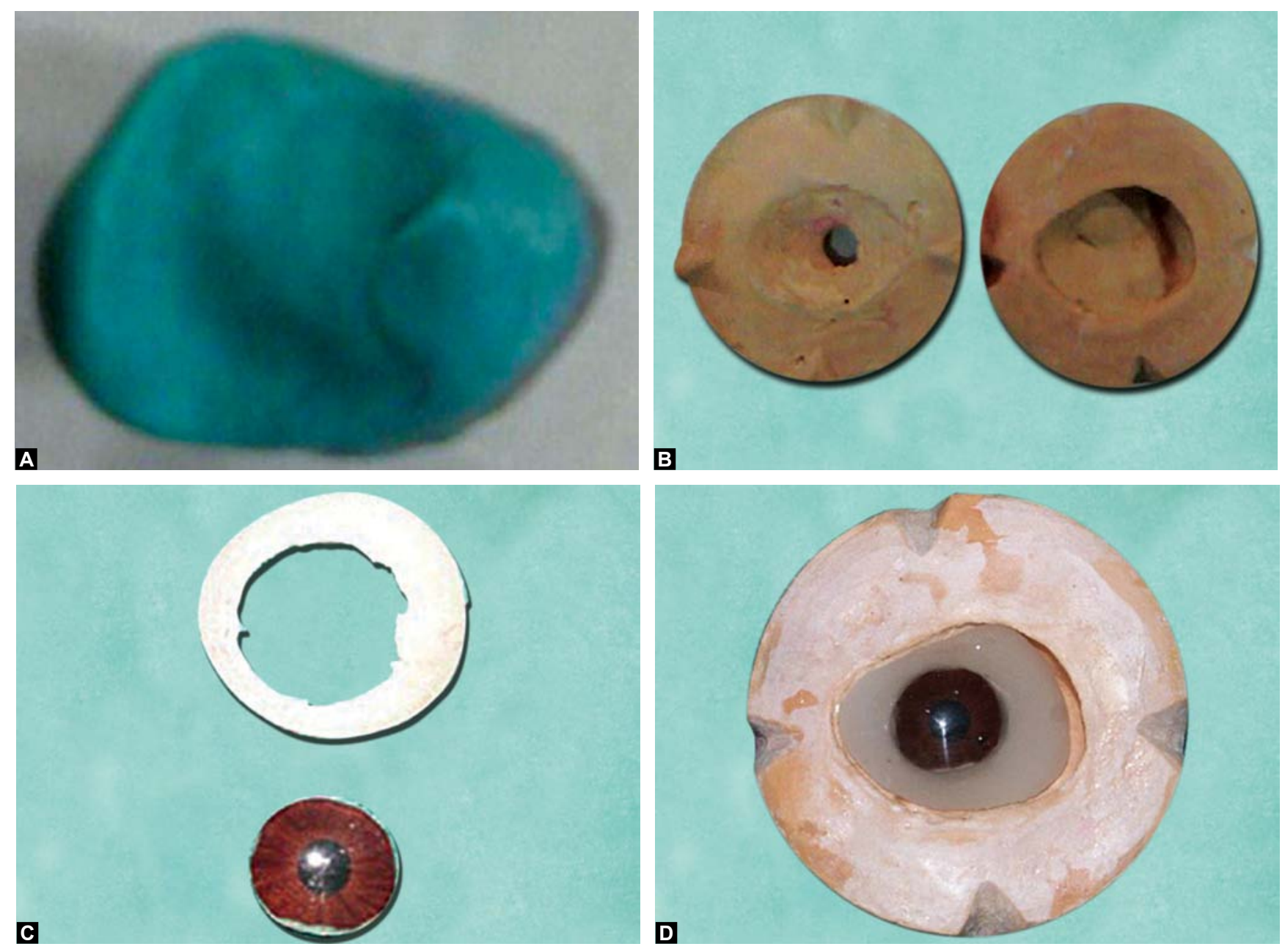

Figs 3A to D: Laboratory steps for waxed ocular prosthesis: (A) ocular impression, (B) split cast, (C) color-matched iris, (D) waxed prosthesis

was cut from the stock eye shell and placed in the respective position on the wax sclera blank (Fig. 3D). Finally, the prosthesis was tried in the orbital socket to compare with the contralateral eye for eyelid fullness, iris size, color and its position in the sclera blank.

Small quantity of autopolymerizing resin (RR-cold cure, DPI, India) in the shape of a button was attached at the center of iris and flasking was done with dental plaster (Fig. 4A). The wax sclera blank was then replaced with white colored heat-cured acrylic resin (Heat cure, DPI, India) by compression molding procedure (Fig. 4B). After polymerization, the prosthesis was removed carefully and the plaster mold was preserved. The resin button attached to the iris was trimmed off with fine carbide bur. The prosthesis was polished, finished and final verification done inside the ocular bed (Fig. 4C). Final verification of the prosthesis in the ocular bed was done after finishing and polishing.

To characterize the prosthesis, 0.5 to $1 \mathrm{~mm}$ of acrylic resin over the sclera surface was trimmed off leaving the iris intact. Small segments of pink color silk threads were twisted and attached over the trimmed sclera surface with a coating of transparent nail polish (Clear glass nail polish 012, Lakme, Hindustan Unilever Ltd., India) (Fig. 4D). Later, the lost thickness of sclera was replaced with clear heat cure resin (Heat Cure, DPI, India) using the preserved mold (Fig. 4E).

The characterized prosthesis inserted into the eviscerated socket (Fig. 5). The patient was comfortable and satisfied with the prosthesis. The easy steps of insertion and removal of the prosthesis was demonstrated to the patient. Instruction for periodic removal and cleaning of prosthesis as well as tissue bed was given to the patient. Follow-up was done after 1 week, 1 and 3 months.

\section{DISCUSSION}

The disfigurement associated with the loss of ocular tissue keeps a person away from social and professional activities. Maxillofacial prosthodontist plays a vital role in bringing back such patients to a normal social life by restoring the lost ocular tissue with artificial substitutes.

Literatures have suggested many techniques for the fabrication of ocular prosthesis. Stock eye shell, relining a 

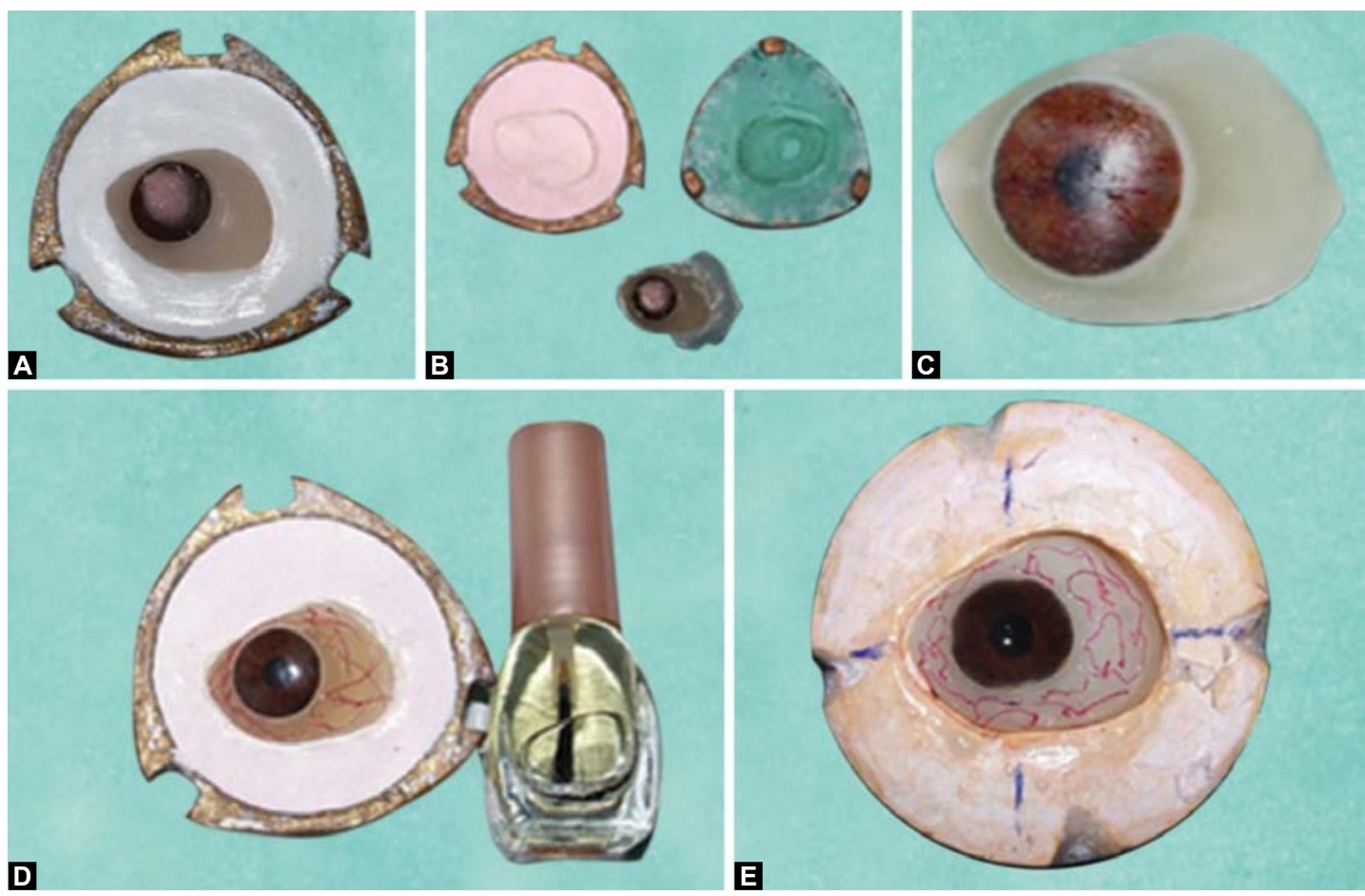

Figs 4A to E: Acralization of ocular prosthesis and characterization procedure: (A) flasking method, (B) deflasked prosthesis, (C) polished prosthesis, (D) silk thread and transparent nail polish, (E) characterized prosthesis

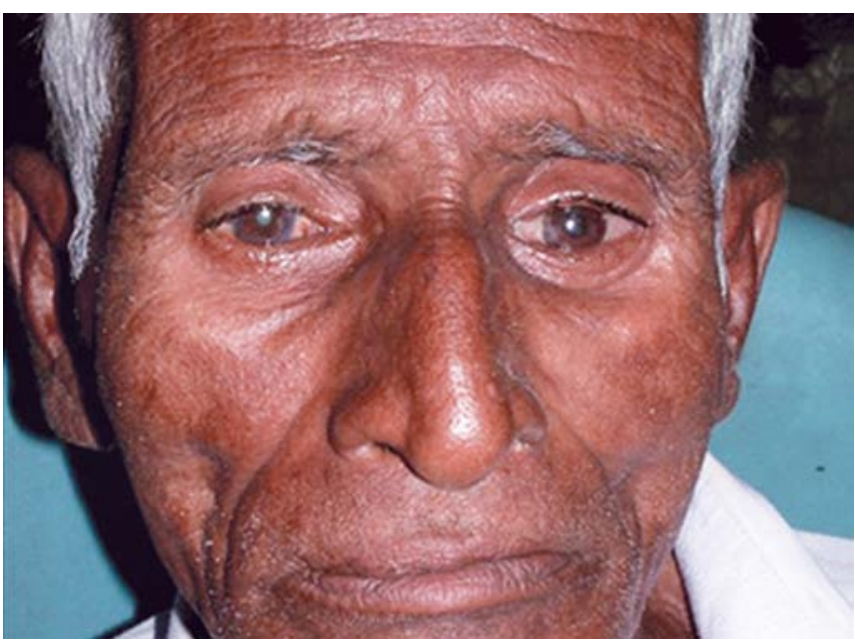

Fig. 5: Postoperative photograph

stock eye shell or custom ocular prosthesis is various types of prosthesis which are currently in use. ${ }^{7,8}$

Stock eye prosthesis was advocated by Laney and Gardner. ${ }^{9}$ In comparison to custom ocular prosthesis, stock prosthesis has several disadvantages, for example poor fit, constant tissue irritations due to bacterial growth in the accumulated fluid in tissue prosthesis interface and compromised esthetic outcome. ${ }^{10-13}$ Relining a stock eye shell can improve the fit of the prosthesis to underlying tissue, while sclera contour and iris position would still be compromised. ${ }^{12}$ Whereas custom ocular prosthesis provides good fit, enhanced esthetics, proper eyelid fullness, accurate sclera contour and iris color match and positioning.
Polymethyl methacrylate resin (PMMA) and glass are generally used for custom ocular prosthesis fabrication. When compared to glass, PMMA has several advantages like easy availability, simplified fabrication method and less chance of breakage. Therefore, PMMA resin is commonly used for ocular prosthesis fabrication. ${ }^{14}$ The custom ocular prostheses are more preferable than stock eye prosthesis because of its improved fit, less fluid accumulation in tissue prosthesis interface, better comfort and esthetic result. ${ }^{15-17}$

Techniques reported in literature for custom ocular prosthesis include black iris disk or painting on iris disk, and paper iris disk with digital photography. Painting on iris disk requires more laboratory time and demands a clinician with high artistic skill and good knowledge about color. ${ }^{5}$ while expensive equipments and knowledge about advanced computer software are needed for digital photography method. ${ }^{18}$

Ocular implant placed in the orbit provides attachment for the rectus muscle which aids in the motility of ocular prosthesis similar to natural eye. Movement of ocular prosthesis provides muscular stimulation for orbital growth in a growing child. ${ }^{19}$ High cost and long treatment duration are the major drawbacks of ocular implants.

In this case report, PMMA iris disk with similar color, size and shape of contralateral natural eye was cut from a stock eye shell and used to fabricate custom ocular prosthesis. Use of color matched PMMA iris disk in the fabrication of ocular prosthesis presents several advantages as compared 
to conventional paint on iris technique. The matched stock iris provides acceptable esthetics and requires minimal modification. The method is simple, less time-consuming, requires minimal artistic skill and knowledge about color and eliminates complex time consuming painting procedure. As compared to digital photography, this technique does not demand expensive equipments.

Because of high cost of ocular implant and advanced age of the patient, ocular implant was not used in this patient. In laboratory phase, autopolymerizing resin in the shape of a button was attached on the top of the iris disk. This buttonshaped resin stabilizes the iris disk in plaster mold.

Since a stock iris disk was used in this method, the esthetic quality of the prosthesis though acceptable, may not be as convincing as the painted iris disk or digital photography methods. So, in young patients and in patients with high esthetic demand, this technique would be less appropriate than the conventional methods.

\section{REFERENCES}

1. Kale E, Meşe A, Izgi AD. A technique for fabrication of an interim ocular prosthesis. J Prosthodont 2008 Dec;17(8):654-661.

2. Ow RK, Amrith S. Ocular prosthetics: use of a tissue conditioner material to modify a stock ocular prosthesis. J Prosthet Dent 1997 Aug;78(2):218-222.

3. Newton JT, Fiske J, Foote O, Frances C, Loh IM, Radford DR. Preliminary study of the impact of loss of part of the face and its prosthetic restoration. J Prosthet Dent 1999 Nov;82(5):585-590.

4. Perman KI, Baylis HI. Evisceration, enucleation, and exenteration. Otolaryngol Clin North Am 1988 Feb;21(1):171-182.

5. Taylor, TD. Clinical maxillofacial prosthetics. Chicago, Illinois: Quintessence Publishing Co, Inc; 2000. p. 233-276.

6. Helland M. Fabrication of ocular prostheses. In: Beumer J, III; Curtis TA, Firtell DN. editors. Maxillofacial rehabilitation: prosthodontic and surgical considerations. St. Louis: CV Mosby; 1979. p. 352-362.

7. Taicher S, Steinberg HM, Tubiana I, Sela M. Modified stock-eye ocular prosthesis. J Prosthet Dent 1985 Jul;54(1):95-98.

8. Benson P. The fitting and fabrication of a custom resin artificial eye. J Prosthet Dent 1977 Nov;38(5):532-538.

9. Laney, WR.; Gardner, AF. Maxillofacial prosthetics. 2nd ed. Littleton: PSG Publishing; 1979. p. 279-306.

10. Sykes LM. Custom-made ocular prostheses: a clinical report. J Prosthet Dent 1996 Jan;75(1):1-3.
11. Welden RB, Niiranen JV. Ocular prosthesis. J Prosthet Dent 1956;6:272-278.

12. Smith RM. Relining an ocular prosthesis: a case report. J Prosthodont 1995 Sep;4(3):160-163.

13. Bartlett SO, Moore DJ. Ocular prosthesis: a physiologic system. J Prosthet Dent 1973 Apr;29(4):450-459.

14. Erpf SF. Comparative features of plastic and/or glass in artificialeye construction. AM Arch Ophthalmol 1953 Dec;50(6):737-744.

15. Brown KE. Fabrication of an ocular prosthesis. J Prosthet Dent 1970 Aug;24(2):225-235.

16. Cain JR. Custom ocular prosthetics. J Prosthet Dent 1982 Dec;48(6):690-694.

17. Schneider RL. Modified ocular prosthesis impression technique. J Prosthet Dent 1986 Apr;55(4):482-485.

18. Jain S, Makkar S, Gupta S, Bhargava A. Prosthetic rehabilitation of ocular defect using digital photography: a case report. J Indian Prosthodont Soc 2010 Sep;10(3):190-193.

19. Beumer J III, Curtis TA, Marunick MT. Ocular implants. Complications. Maxillofacial rehabilitation: prosthodontic and surgical considerations. St. Louis: CV Mosby; 1979. p. 348-352; p. 362-364.

\section{ABOUT THE AUTHORS}

\section{Nitai Debnath (Corresponding Author)}

Senior Lecturer, Department of Prosthodontics, College of Dental Science and Hospital, Indore, Madhya Pradesh, India, Phone: 8305929262 e-mail: dr.nitai08@gmail.com

\section{Renu Gupta}

Consultant, Department of Periodontics, Nair Hospital and Dental College, Mumbai, Maharashtra, India

\section{A Meenakshi}

Professor, Department of Prosthodontics, Tamilnadu Government Dental College and Hospital, Chennai, Tamil Nadu, India

\section{K Ramkumar}

Assistant Professor, Department of Prosthodontics, Tamilnadu Government Dental College and Hospital, Chennai, Tamil Nadu, India

\section{Jiji John}

Professor, Department of Periodontics, College of Dental Science and Hospital, Indore, Madhya Pradesh, India 